\title{
Lifestyle after Cardiac Rehabilitation: Did the Message Come across, and Was It Feasible? An Analysis of Patients' Narratives
}

\author{
Marie Veje Knudsen ${ }^{1,2}$, Sussie Laustsen ${ }^{2,3}$, Annemette Krintel Petersen ${ }^{1,2}$, Sanne Angel ${ }^{4}$ \\ ${ }^{1}$ Department of Physiotherapy and Occupational Therapy, Aarhus University Hospital, Aarhus, Denmark \\ ${ }^{2}$ Centre of Research in Rehabilitation (CORIR), Department of Clinical Medicine, Aarhus University Hospital and \\ Aarhus University, Aarhus, Denmark \\ ${ }^{3}$ Department of Cardiothoracic and Vascular Surgery, Aarhus University Hospital, Aarhus, Denmark \\ ${ }^{4}$ Section of Nursing, Department of Public Health, Aarhus University, Aarhus, Denmark \\ Email: mariknud@rm.dk
}

Received 7 September 2014; revised 22 October 2014; accepted 7 November 2014

Copyright (C) 2014 by authors and Scientific Research Publishing Inc.

This work is licensed under the Creative Commons Attribution International License (CC BY).

http://creativecommons.org/licenses/by/4.0/

(c) (i) 0pen Access

\section{Abstract}

Lifestyle following heart disease is considered important to prevent and reduce cardiovascular risk factors. Thus, cardiac rehabilitation is focused on potential lifestyle changes. Further insight into patients' perspective on lifestyle after cardiac rehabilitation is needed as changing habits following heart disease is a complex matter. The objective of this study was to explore the characteristics of lifestyle after cardiac rehabilitation. A phenomenological-hermeneutic approach with qualitative interviews was performed in 20 patients six months after completing a hospital-based cardiac rehabilitation programme in 2012 at Aarhus University Hospital, Denmark. The patients were diagnosed with ischemic heart disease, heart failure or left heart valve disease. The interviews were analysed using the interpretation theory by Ricoeur. The variation in reactions to cardiac rehabilitation were: 1) considering prior lifestyle to be appropriate, maybe with minor adjustments; 2) acknowledging the need for incorporating lifestyle changes; and 3) reconciling or feeling guilt when being unable to manage changes. Participation in the cardiac rehabilitation programme was a positive experience, but it had minor influence on long-term adherence to recommended lifestyle. The important thing in establishing new routines was whether they aroused interest, and whether the experience of changes was perceived as necessary and manageable. In future cardiac rehabilitation, focusing on patients' interests and supporting them in incorporating recommendations into their everyday life might be essential following heart disease, also after ending cardiac rehabilitation.

\footnotetext{
"Corresponding author.
}

How to cite this paper: Knudsen, M.V., Laustsen, S., Petersen, A.K. and Angel, S. (2014) Lifestyle after Cardiac Rehabilitation: Did the Message Come across, and Was It Feasible? An Analysis of Patients' Narratives. Health, 6, 2641-2650. 


\section{Keywords}

\section{Cardiac Disease, Cardiac Rehabilitation, Lifestyle Change, Qualitative Study}

\section{Introduction}

To get on with life following a chronic heart disease implies both physical and mental challenges. Cardiac rehabilitation is well recognized as facilitating recovery following heart disease, and rehabilitation plays an important role for the patient's prognosis [1] [2]. Rehabilitation primarily aims at modifying cardiovascular risk factors through dietary changes, smoking cessation, physical exercise, and psychosocial support [1] [2]. However, change of habits and lifestyle is a complex matter [3]; this complexity can be related to different barriers. In a literature review including 33 qualitative studies from 1986-2009 Murray et al. identified five major barriers to lifestyle changes: 1) the emotional state, mostly related to motivation, stress, confidence and embarrassment; 2) beliefs about the need to make changes; 3) knowledge about lifestyles; 4) support from family and friends; and 5) practical issues such as daily costs of living [4]. These findings support that consideration of both psychological and practical barriers are paramount to manage lifestyle changes.

The most challenging part of rehabilitation is to empower patients to continue and maintain a healthy lifestyle after terminating the rehabilitation programme. Fletcher et al. found that patients could feel alone and unsupported after completing the cardiac rehabilitation programme [5]. Furthermore, Pryor et al. reported that support from both healthcare professionals and family and friends was important to manage a new way of life [6]. However, even 12 months after completing a cardiac rehabilitation programme, White et al. identified that many patients still had unresolved concerns about lifestyle changes [7]. This indicates that the planned rehabilitation programme was ended before the patients were able to manage lifestyle changes. Unmet needs may, according to a Danish study, be explained by diversity among the population with heart disease based on socioeconomic status and psychosocial risk factors resulting in a need for differentiated cardiac rehabilitation [8]. Knowledge of the diversity within this population could be considered and incorporated in the rehabilitation programme. This may call for an evaluation of the programme concerning length, focus, and content. Thus, healthcare professionals might consider a more tailored approach to lifestyle changes during rehabilitation. Before any adaptations are made there is a need for further exploring the patients' perspective on cardiac rehabilitation. Studies have tended to focus on the experience of living with a heart disease and barriers to cardiac rehabilitation attendance [9] [10]. Insight into patients' perspective on lifestyle changes will facilitate understanding of the complexity of managing a new lifestyle, especially after completion of a cardiac rehabilitation programme. For the healthcare professionals, patients' perspective on lifestyle changes can contribute to developing and optimising rehabilitation programmes and personal support to patients with heart disease.

\section{Aim}

The aim of this study was to explore patients' perspective on characteristics of lifestyle after cardiac rehabilitation.

\section{Methods}

A phenomenological-hermeneutic approach was used to gain insight into life following heart disease.

\subsection{The Recommendations for a Healthy Lifestyle Following Heart Disease}

The recommendations in the rehabilitation programme complied with the advice from the Danish Health and Medicines Authority [11]. During cardiac rehabilitation, participants attended theoretical lessons with the physiotherapists, nurses and the dietician about having a heart disease, treatment, medication, and recommendations for a healthy lifestyle. The importance of a healthy lifestyle was explained in relation to avoiding a new cardiac event and to improve participants' prognosis. Groups of 10 to 12 participants were educated about their disease and lifestyle including diet, physical exercise, smoking cessation, and alcohol consumption. The diet recommended was a varied and low-fat diet containing fruit, vegetables, fish, wholemeal and a minimum of saturated 
fat and salt intake. Aerobic workout should be accomplished at least twice a week for 20 minutes. Further recommendations were smoking cessation and to follow national recommendations concerning consumption of alcohol.

\subsection{Participants}

In 2012, a sample of 20 participants was invited to the interview six months after completion of the cardiac rehabilitation programme at Aarhus University Hospital, Denmark. The participants were diagnosed with ischemic heart disease, heart failure or left heart valve disease (Table 1). The participants were invited to the interview on the last day of their rehabilitation programme and they all accepted the invitation. The interviews were conducted either in the participants' homes, at the hospital or at the researcher's office.

\subsection{Interviews}

With a narrative approach, the interviewer elicited the participants' stories about their experiences of life with heart disease, the rehabilitation and the understanding of their present health situation. The narratives were collected to gain insight into the participants' interpretation and meaning making based on Ricoeur's philosophy of narratives [12] [13]. The interviews were ended with questions related to the participants' experiences with the rehabilitation programme; their own perception of what was successful/unsuccessful in their participation, and whether they would recommend the programme to others. Finally, the participants were invited to express further experiences of importance about their situation if these had not already been clarified during the interview.

Table 1. Demographic characteristics of participants six months after completing a cardiac rehabilitation programme at Aarhus University Hospital, Denmark.

\begin{tabular}{|c|c|c|c|}
\hline Name & Treatment & Marital status & Working status \\
\hline Arne & Valve & Married & Employed \\
\hline Bent & PCI & Married & Employed \\
\hline Claus & CABG & Married & Employed \\
\hline Dan & PCI & Married & Pensioner \\
\hline Ejnar & PCI & Married & Employed \\
\hline Fin & CABG & Married & Employed \\
\hline Gert & PCI & Single & Early retirement \\
\hline Henrik & Valve & Married & Employed \\
\hline Ivan & $\mathrm{CABG}+\mathrm{PM}$ & Married & Employed \\
\hline Jan & Valve & Married & Employed \\
\hline Andrew & PCI & Married & Pensioner \\
\hline Bob & Valve & Married & Employed \\
\hline Christopher & CABG & Married & Pensioner \\
\hline Denise & CABG & Married & Employed \\
\hline Elisa & $\mathrm{PCI}+\mathrm{CABG}$ & Married & Pensioner \\
\hline Francis & Valve + PM & Married & Employed \\
\hline Gregor & PCI & Married & Early retirement \\
\hline Harry & CABG & Single & Employed \\
\hline Irene & Valve + CABG & Widow & Pensioner \\
\hline James & AMI & Married & Employed \\
\hline
\end{tabular}

AMI: Acute myocardial infarction; CABG: Coronary artery bypass grafting; PCI: Percutaneous coronary intervention; PM: Pacemaker; Valve: Left heart valve surgery. 


\subsection{Data Analysis}

The transcribed interviews were analysed using the interpretation theory by Ricoeur [12] [13]. This implied three levels of textual analysis; naïve reading, structural analysis and critical interpretation. In order to discuss and understand the content of the narratives, the transcripts were read and reread independently by two interpreters. In the naïve readings the aim was to understand the meaning of having a heart disease. The heart disease started a process with reconsiderations about life and lifestyle whether or not the heart disease had been experienced as life threatening.

In the structural analysis we carefully examined each interview to understand the participants' story. The analysis went from what the participants told to an understanding of what was meant. On the basis of the 20 participants' narratives, five major themes occurred: 1) having a heart disease; 2) the medical treatment as complicated/uncomplicated; 3) ready for/not being ready for discharge from hospital; 4) the importance attached to the rehabilitation programme and 5) reconsidering life including establishment of new routines and maintaining lifestyle changes.

All narratives were compared and contrasted and the significant structure within the variations concerned the experience of reconsidering life and lifestyle. In the critical interpretations we reached the most significant interpretation of how the participants managed life following heart disease. The interpretation was related to the recommendations concerning healthy lifestyle included in the cardiac rehabilitation programme. In order to do this, we discussed the findings until a decision was made on the most coherent and plausible interpretation in line with Ricoeur's theory.

\subsection{Ethics}

The study was notified to The Central Denmark Region Committee on Biomedical and Research Ethics (no. 33883), and The Danish Data Protection Agency (no. 2007-58-0010). All participants gave informed consent to participate based on written and oral information. Personal data were handled in accordance with rules on confidentiality.

\section{Results}

Despite communicating identical recommendations about healthy lifestyle during the cardiac rehabilitation programme, the narratives revealed different perceptions of the necessary lifestyle changes needed to avoid new cardiac events. The participants expressed the same understanding of the recommendations concerning diet, smoking and alcohol, but the participants' understanding of the intensity and frequency of physical exercise differed. Furthermore, the narratives were not concerned about smoking or alcohol habits, but about managing exercise and dietary changes.

The variations in reactions to cardiac rehabilitation were: 1) considering prior lifestyle to be appropriate, maybe with minor adjustments; 2) acknowledging the need for and incorporating lifestyle changes; and 3) reconciling or feeling guilt when being unable to manage changes. The core issues were whether the participants understood the message, and were able to incorporate the recommendations into their everyday life.

\subsection{Considering Prior Lifestyle to Be Appropriate, Maybe with Minor Adjustments}

Some participants considered the healthy lifestyle recommended in cardiac rehabilitation to be equal to their lifestyle before the heart disease. This was reported whether participants were diagnosed with ischemic heart disease, heart failure or left heart valve disease.

\section{1) Exercise}

The cardiac rehabilitation programme played an important role for the participants' ability to resume prior lifestyle. Being able to live life almost as before without any heart symptom was experienced as safe and as having fully recovered. One of the participants, James, could easily perform physical activities as before the heart disease; bowling, doing fitness, and gardening. Not having any physical limitations made him feel safe and healthy again.

Despite narratives reporting confidence in the surgery having solved the heart problem, some found it frightening and unsafe to get on with life following heart disease. Here, the cardiac rehabilitation programme was a great help. The importance was to recover physical capacity during exercise. Another participant, Francis, had 
tried resuming his running before starting the cardiac rehabilitation programme. His initial fear of the heart working too hard resulted in a need to know that he could manage the physical exercise programme. During the rehabilitation programme he began to feel safe and at the end of the programme he could run 10 kilometres again. This had shown him that he had regained control of his body, and it convinced him that after all his heart had not failed him. He described this as a feeling of increased self-confidence.

The instructions in challenging the aerobic workout led to a new consciousness for some. The importance of this made Claus and Dan continue their previous physical exercises in an intensified way. Claus told that he had become increasingly aware of changing his sedentary lifestyle. Dan got a new perspective on exercise since he had never thought of challenging his aerobic workout performance before he attended the rehabilitation programme.

Not everyone followed the recommended intensity for aerobic physical exercises and the result was not always a challenging workout. But, some participants believed that they were doing it right. Thus, they maintained their previous lifestyle thinking that their physical exercises equalled what was recommended despite lack of aerobic workout. However, from the participants' perspective, maintenance of previous lifestyle, maybe with minor adjustments, gave positive expectations to recover following heart disease.

2) Diet

Some of the participants who maintained previous lifestyle did not participate in the dietary lesson in the rehabilitation programme. These participants argued that they already knew about dietary recommendations from either national recommendations and own or spouse's previous counselling on health issues. However, some of those who attended the lesson appreciated getting the recommendations repeated. James was interested in knowing if he could learn something new despite believing that he had a healthy lifestyle. He asked several questions during the lesson and referred to his daily routines and dietary intake. In this way he felt that the lesson was individualised because he was instructed on how to get an even healthier lifestyle. This made him feel safe and satisfied knowing that he could improve his effort to prevent a new cardiac event.

\subsection{Acknowledging the Need for and Incorporating Lifestyle Changes}

Some participants found the new routines meaningful and they managed through motivation expressed as being satisfied with being on the right track after their heart disease.

1) Exercise

The recommended physical exercise became an appreciated routine to some as it created a sense of well-being. Arne had been fond of biking but had only had little time for it. The recommendations during cardiac rehabilitation caused him to prioritise differently. After the heart disease he considered to stop allowing his work to take up such a major part of his time. Consequently, he now leaves work early once a week to make time for exercise; he expressed well-being as a result of the regular biking. Arne's motivation was training for a bike race, and exercising together with friends. This combination gave an extra positive dimension with enjoyment and a sense of community.

The rehabilitation programme could also reveal unknown benefits such as being able to do more physical exercise than anticipated. Challenged by the physiotherapists, Andrew was encouraged to test his exercise capacity, which resulted in a regular exercise routine.

To others exercise was rather new, and the rehabilitation programme opened up a new world. Irene, an elderly woman, was thrilled about her physical improvements and became an ambassador for exercising among her peers. To her, attending the programme was a positive experience in a difficult period of life feeling lonely and disheartened. Through the physical exercise programme she regained both physical and mental strength. Attending the local fitness centre gave her a new social network, which helped her recover.

Finding a type of exercise that aroused interest was important; then it was possible to incorporate physical exercise as a routine and to follow recommendations even after ending cardiac rehabilitation. This did not depend on whether having experience with exercise before the heart disease.

2) Diet

The importance of participating in the dietary lesson was the suggestions on how to manage dietary changes. It was important to find a balance between a healthy diet and previous dietary habits and most importantly, to get a feeling of being on the right track concerning dietary changes. Ivan found the lessons to be a great support during his dietary change, especially learning about the healthy alternatives. This made him feel satisfied and motivated knowing that he could affect his life and improve his health. Others were introduced to interpreting 
labels on food indicating fibre and fat content; this made it easier to choose healthy products.

\subsection{Reconciling or Feeling Guilt When Being Unable to Manage Changes}

The participants unable to manage lifestyle changes fell in two groups: Some were reconciled despite knowing that they did not follow the recommended healthy lifestyle; in others it created inner conflicts with frustration and maybe even feelings of guilt, shame and insecurity.

\subsubsection{Reconciliation despite Deviation from the Recommendations}

Some knew that they did not follow all the recommendations from the cardiac rehabilitation programme. Living a life where they did not worry about having a new cardiac event was expressed as reconciliation.

1) Exercise

The reconciliation seemed to be achieved if there were acceptable explanations like other unchangeable physical health limitations. Christopher had a chronic disease requiring medical treatment several times a week. He found it impossible to incorporate extra time for exercise. Instead, he and his wife tried to do some workout when going for a walk. Even though Christopher knew it was not enough to improve his physical capacity he reconciled with this because he thought his chronic disease was the primary problem and the cause of his reduced effort.

To others reconciliation was experienced when returning to everyday life. Bob prioritised his work and tried not to worry about having another cardiac event. His wife made an effort of getting him to do more exercise. Bob believed, though, that the surgery had solved his heart disease and that this in combination with cardiac rehabilitation attendance would keep him safe.

2) Diet

Dietary changes could be difficult if cooking and food in general had a low priority. Sometimes not even prolonged elevated blood cholesterol level and individual consultations with the dietician helped. Harry had a prejudiced assumption of the dietician's recommendations, which sounded so easy; to Harry they were difficult. To him, as a single man, the meal was typically something fast and simple because food was not his interest.

\subsubsection{Inner Conflicts Regarding the Recommendations}

Despite good intentions and possibilities to adapt to a routine, some of the participants could not manage to change their lifestyle. The inability to follow the recommendations for a healthy lifestyle could lead to an inner conflict, guilt, shame and dissatisfaction with oneself.

1) Exercise

Attending to the exercise rehabilitation programme and experiencing being left in a limbo when finishing cardiac rehabilitation showed the significance of physiotherapeutic support. For Gregor the guidance made it possible to exercise despite back pain, because the physiotherapists offered him alternatives exercises. Gregor could not have managed this without support. He was dissatisfied not being capable of managing new routines after finishing cardiac rehabilitation.

Others could not manage the changes, despite good intentions and the possibility to get a new routine for a healthy lifestyle. Ejnar did not do any exercise even though there were fitness facilities at his workplace. He explained the inner conflict of knowing that he had lots of possibilities to exercise. He really appreciated having somebody to exercise with because he found it helpful that others showed up and expected him to participate, but none of his colleagues from work joined him.

Being unable to maintain an exercise routine affected some of the participants when meeting with the physiotherapist at the six-month follow-up. Elisa's increasing tiredness resulted in a reduced effort and a reduced aerobic capacity. She expressed a feeling of shame because of the unsatisfying result caused by her inability to maintain an exercise routine on her own.

2) Diet

Dietary changes were experienced difficult or overwhelming. Fin had never eaten vegetables before, and the taste and especially the preparation of the vegetables was a challenge. His inner conflict was expressed as knowing what to do but being unable to follow the recommended diet. Instead of eating vegetables, he stopped using fat when frying and he never ate sauce with his beef and potatoes. However, cutting things out of his diet resulted in reduced enjoyment of the meal. Gregor wished to lose weight, but he did not know where to start and 
how to deal with lifestyle changes. He loved food but to him, inability to keep self-control could lead to guilt because he failed to manage the recommended lifestyle.

To others changing dietary habits was overwhelming. Bent was not only chronically ill with a heart disease but was also newly diagnosed with diabetes. To him, dietary changes were radical, and he had to give up too much of his favourite food. This was overwhelming, because he could not find a balance between his previous and the recommended lifestyle. He was disappointed that he was unable to change lifestyle; this meant that he had given up and continued his previous dietary habits.

\section{Discussion}

The interpretations revealed that some of the participants considered their previous lifestyle to match the recommendations of the rehabilitation programme. Others found it important to adjust their lifestyle to keep healthy and avoid a new cardiac event. This was successful for some, while others were reconciled with living a life that made sense to them. Not succeeding in adapting to new routines could lead to an inner conflict and dissatisfaction with oneself. However, the core in establishing new routines was when a positive experience led to wellbeing.

\subsection{Considering Prior Lifestyle to Be Appropriate, Maybe with Minor Adjustments}

Getting back to an everyday life following heart disease was important. This was expressed as returning to work, resuming previous activities and the ability to take care of oneself. However, having been confronted with a life threatening disease meant that life had to be lived with the awareness of doing what is right to stay healthy. According to Paterson et al. symptoms can guide the patients to stay healthy: Not following recommendations, symptoms become overwhelming; when there are no symptoms, it is seen as a sign of the importance of following recommendations [14]. This might explain why some of our participants experienced that they had recovered and were safe. They could believe that not having any heart symptoms when living a life almost as before was equivalent to the recommended healthy lifestyle. Furthermore, some of the participants did not perceive the heart disease as an event that was caused by their lifestyle; however, the narratives showed that the patients' own understanding of and perspective on their lifestyle influencing their heart disease were not always realistic.

\subsection{Acknowledging the Need for and Incorporating Lifestyle Changes}

Having experience with exercise before the heart disease was an advantage, but the important thing was to arouse the participants' interest in exercising. Engaging in physical exercise led to the desire to manage a new lifestyle and encouraged participants to continue. The safe environment and community in cardiac rehabilitation attendance as well as the social aspect have previously been described as significant [6] [15]-[18]. Meeting with peers and creating new friendships can be supportive after finishing rehabilitation [6]. Thus, the value of being with other cardiac patients, sharing experiences and the supportive environment could be significant factors in successful cardiac rehabilitation. However, our study revealed that the social aspect was appreciated, but it was not the main reason for changing lifestyle. This is in line with Kristofferzon et al. reporting that characteristics for managing lifestyle changes were about negotiating with oneself, relying on own capabilities, and behavioural changes [19]. This points to the importance of an individual approach to guide this process, and a professional focus on how to support this challenging process also after finishing cardiac rehabilitation.

\subsection{Reconciling or Feeling Guilt When Unable to Manage Lifestyle Changes}

Some of the participants were reconciled despite knowing that they did not follow all recommendations. The reconciliation seemed not only to be achieved if there were acceptable explanations like other unchangeable physical health limitations such as a chronic disease. The reconciliation seemed possible because life seemed to work for them in relation to health and well-being. Leventhal et al. stressed that if patients do not have symptoms from their heart disease it can be hard to maintain the focus on the necessity to change lifestyle; patients take special notice of their experience and perceptions of somatic changes in themselves, and this affects how patients manage their chronic disease [3]. This might explain the reconciliation found in our study; not following the recommendations did not necessarily lead to heart symptoms, which could make it difficult to understand the necessity of lifestyle changes. 
If exercise did not arouse interest, the participants had difficulties in transferring the changes from a structured, supportive environment in the cardiac rehabilitation to their everyday lives. Tully et al. found patients' motivation lapsed once the cardiac rehabilitation ended, especially concerning maintenance of an exercise routine; they experienced patients to be lacking direction when the rehabilitation programme ended [20]. Patients who had difficulties in maintaining motivation for changes after cardiac rehabilitation could feel abandoned and unsupported in their efforts once the programme finished [5]. Thus, being unable to change lifestyle due to lack of motivation and insecurity was caused by patients not being able to establish new routines before the rehabilitation programme ended.

Trying to establish new routines could be overwhelming due to lack of energy or because it did not affect well-being. Managing this after cardiac rehabilitation was challenging and the feeling of being left in a void indicates a need for further guidance. Previous studies have described patients articulating the need for further support and advice following cardiac rehabilitation, not only in relation to physical exercise but when incorporating new routines in general [6] [7] [10]. Being unsuccessful in managing lifestyle changes and not do as recommended could create an inner conflict. This seemed especially challenging when the changes were overwhelming, difficult, unpleasant, and not an interest of the patient. Condon et al. observed that making too many changes at the same time might be unrealistic in the long term when adopting new routines [10]. Instead they suggested that adherence to changes may be more successful if focusing on one change and to implement this successfully. Thus, realistic goal setting involving the patients' perspective could be positive in the struggle for new routines as it gives the patients a sense of control of their own recovery.

Interestingly, our narratives were not concerned about smoking or alcohol habits, but instead focused on managing changes in physical exercise and dietary habits. This might indicate the current focus in cardiac rehabilitation when evaluating the programme. For healthcare professionals, focusing on lifestyle changes with interdisciplinary approaches may contribute to further develop rehabilitation programmes to support patients in managing life following heart disease. Furthermore, attention to the different understandings of aerobic workout between patients is important. Our findings suggest that more emphasis is needed on how each individual can manage to incorporate aerobic workout into their everyday life. Moreover, the results suggest that focus is needed on ways of providing dietary information that encourages adapting to a balanced diet [21].

\subsection{Study Limitations/Methodological Considerations}

The participants' experiences could have been explored in more than one interview to further understand the complexity of lifestyle changes. Though our focus was the patients' experiences, it could have been interesting to know more in detail how they managed their lifestyle. The narratives could be interpreted as if some of the participants did more than recommended, while others did less, but perceived the changes as equivalent to the recommended lifestyle in the rehabilitation programme. Furthermore, the participants had all completed the cardiac rehabilitation programme. Thus, the study is not concerned with perspectives on lifestyle in those not participating or not completing a cardiac rehabilitation programme. Future research should explore characteristics of lifestyle following heart disease in those who do not attend cardiac rehabilitation. Insight into this field would be an important contribution in the evaluation of existing rehabilitation programmes and may identify unmet rehabilitation needs.

\subsection{Conclusion}

Establishing new routines following heart disease was a major challenge, but it could be a positive experience if considering the participants' interests and abilities. If not succeeding in establishing new routines, the reason could be that recommendations demanded more effort and deprivation than that could be accepted. This could lead to guilt and dissatisfaction. The healthcare professionals played an important role during rehabilitation. However, the narratives also identified a need for further support and advice after finishing the cardiac rehabilitation programme. Here, realistic goal setting during rehabilitation involving the patients' perspective could be positive when trying to establish new routines, including focus on incorporating the recommendations into everyday life.

\section{Acknowledgements}

We wish to thank the participants for sharing their experiences. 


\section{Funding}

The work was supported by the Lundbeck Foundation (grant number FP48/2009); the National Funds for Chronic Diseases in Denmark; and The Novo Nordisk Foundation (grant number 7267).

\section{Declaration of Conflicting Interests}

None declared.

\section{References}

[1] Piepoli, M.F., Corrà, U., Benzer, W., et al. (2010) Secondary Prevention through Cardiac Rehabilitation: From Knowledge to Implementation. A Position Paper from the Cardiac Rehabilitation Section of the European Association of Cardiovascular Prevention and Rehabilitation. European Journal of Preventive Cardiology, 17, 1-17. http://dx.doi.org/10.1097/HJR.0b013e3283313592

[2] Corrà, U., Piepoli, M.F., Carré, F., et al. (2010) Secondary Prevention through Cardiac Rehabilitation: Physical Activity Counselling and Exercise Training: Key Components of the Position Paper from the Cardiac Rehabilitation Section of the European Association of Cardiovascular Prevention and Rehabilitation. European Heart Journal, 31, 19671974.

[3] Leventhal, H., Weinman, J., Leventhal, E.A., et al. (2008) Health Psychology: The Search for Pathways between Behavior and Health. Annual Review of Psychology, 59, 477-505. http://dx.doi.org/10.1146/annurev.psych.59.103006.093643

[4] Murray, J., Honey, S., Hill, K., et al. (2012) Individual Influences on Lifestyle Change to Reduce Vascular Risk: A Qualitative Literature Review. British Journal of General Practice. http://dx.doi.org/10.3399/bjgp12X649089

[5] Fletcher, S.M., Burley, M.B., Thomas, K.E., et al. (2014) Feeling Supported and Abandoned: Mixed Messages from Attendance at a Rural Community Cardiac Rehabilitation Program in Australia. Journal of Cardiopulmonary Rehabilitation \& Prevention, 24, 29-33. http://dx.doi.org/10.1097/HCR.0b013e3182a52734

[6] Pryor, T., Page, K., Patsamanis, H., et al. (2014) Investigating Support Needs for People Living with Heart Disease. Journal of Clinical Nursing. http://dx.doi.org/10.1111/jocn.12165

[7] White, S., Bissell, P. and Anderson, C. (2010) Patients’ Perspectives on Cardiac Rehabilitation, Lifestyle Change and Taking Medicines: Implications for Service Development. Journal of Health Services Research \& Policy, 15, 47-53. http://dx.doi.org/10.1258/jhsrp.2009.009103

[8] Meillier, L.K., Nielsen, K.M., Larsen, F.B., et al. (2012) Socially Differentiated Cardiac Rehabilitation: Can We Improve Referral, Attendance and Adherence among Patients with First Myocardial Infarction? Scandinavian Journal of Public Health, 40, 286-293. http://dx.doi.org/10.1177/1403494812443600

[9] Clark, A., King-Shier, K., Spalling, M., et al. (2013) Factors Influencing Participation in Cardiac Rehabilitation Programmes after Referral and Initial Attendance: Qualitative Systematic Review and Meta-Synthesis. Clinical Rehabilitation, 27, 948-950. http://dx.doi.org/10.1177/0269215513481046

[10] Condon, C. and McCarthy, G. (2006) Lifestyle Changes Following Acute Myocardial Infarction: Patients' Perspectives. European Journal of Cardiovascular Nursing, 5, 37-44. http://dx.doi.org/10.1016/j.ejcnurse.2005.06.005

[11] Zwisler, A., Madsen, M. and Nissen, N.K. (2006) Cardiac Rehabilitation-A Health Technology Assessment. Evidence from the Literature and the DANREHAB Trial. Copenhagen.

[12] Ricoeur, P. (1990) Time and Narrative. University of Chicago Press, Chicago.

[13] Ricoeur, P. (1976) Interpretation Theory: Discourse and the Surplus of Meaning. Texas Christian University Press, Fort Worth.

[14] Paterson, B.L. (2001) The Shifting Perspectives Model of Chronic Illness. Journal of Nursing Scholarship, 33, 21-26. http://dx.doi.org/10.1111/j.1547-5069.2001.00021.x

[15] Pâquet, M., Bolduc, N., Xhignesse, M. and Vanasse, A. (2005) Re-Engineering Cardiac Rehabilitation Programmes: Considering the Patient's Point of View. Journal of Advanced Nursing, 51, 567-576. http://dx.doi.org/10.1111/j.1365-2648.2005.03544.x

[16] Bergman, E. and Berterö, C. (2003) “Grasp Life Again”. A Qualitative Study of the Motive Power in Myocardial Infarction Patients. European Journal of Cardiovascular Nursing, 2, 303-310. http://dx.doi.org/10.1016/S1474-5151(03)00098-7

[17] Gregory, S., Bostock, Y. and Backett-Milburn, K. (2006) Recovering from a Heart Attack: A Qualitative Study into Lay Experiences and the Struggle to Make Lifestyle Changes. Family Practice, 23, 220-225. http://dx.doi.org/10.1093/fampra/cmi089 
[18] Cooper, A.F., Jackson, G., Weinman, J. and Horne, R. (2005) A Qualitative Study Investigating Patients’ Beliefs about Cardiac Rehabilitation. Clinical Rehabilitation, 19, 87-96. http://dx.doi.org/10.1191/0269215505cr818oa

[19] Kristofferzon, M., Löfmark, R. and Carlsson, M. (2007) Striving for Balance in Daily Life: Experiences of Swedish Women and Men Shortly after a Myocardial Infarction. Journal of Clinical Nursing, 16, 391-401. http://dx.doi.org/10.1111/j.1365-2702.2005.01518.x

[20] Tully, N.E., Morgan, K.M., Burke, H.M. and McGee, H.M. (2010) Patient Experiences of Structured Heart Failure Programmes. Rehabilitation Research and Practice, 2010, Article ID: 157939. http://dx.doi.org/10.1155/2010/157939

[21] White, S., Bissell, P. and Anderson, C. (2011) A Qualitative Study of Cardiac Rehabilitation Patients' Perspectives on Making Dietary Changes. Journal of Human Nutrition and Dietetics, 24, 122-127. http://dx.doi.org/10.1111/j.1365-277X.2010.01136.x 
Scientific Research Publishing (SCIRP) is one of the largest Open Access journal publishers. It is currently publishing more than 200 open access, online, peer-reviewed journals covering a wide range of academic disciplines. SCIRP serves the worldwide academic communities and contributes to the progress and application of science with its publication.

Other selected journals from SCIRP are listed as below. Submit your manuscript to us via either submit@scirp.org or Online Submission Portal.
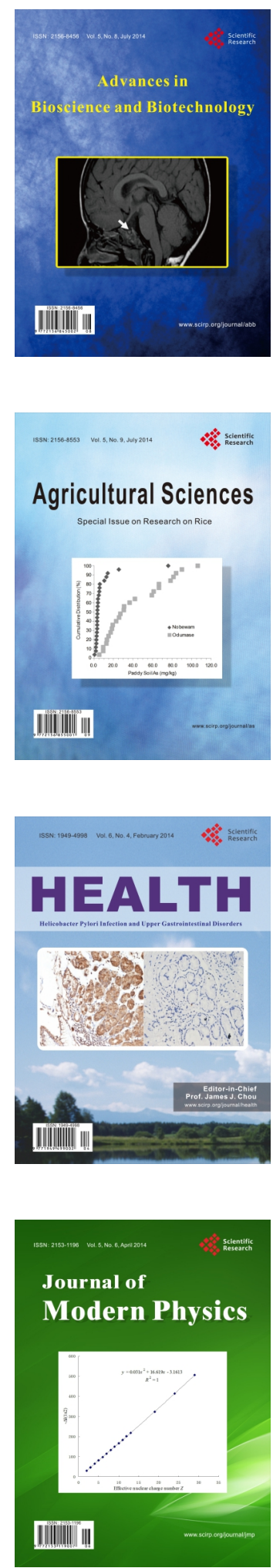
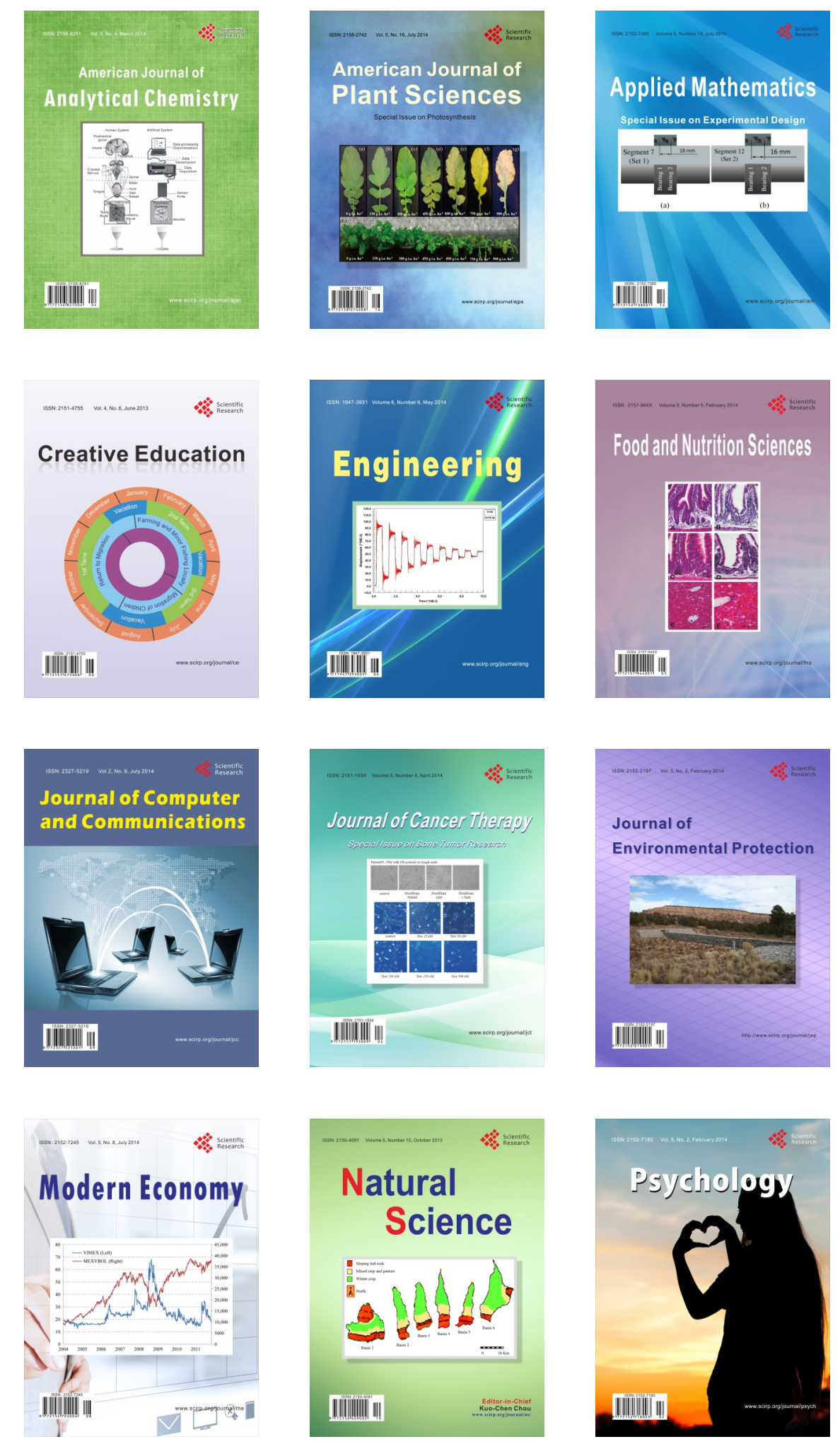